\title{
Relações sociais de sexo/gênero, trabalho e saúde: contribuições de Helena Hirata
}

\author{
Social relations of sex/gender, work and health: contribution of \\ Helena Hirata
}

Simone Santos Oliveira', Mary Yale Neves², Jussara Brito', Lúcia Rotenberg ${ }^{\mathbf{3}}$

DOI: 10.1590/0103-11042021E111

RESUMO O artigo visou refletir acerca da produção intelectual da pesquisadora Helena Hirata como importante referência para o campo da saúde coletiva, em especial para a compreensão das relações entre o trabalhar e as dinâmicas que envolvem a saúde. Recorreram-se às suas publicações teórico-acadêmicas e entrevistas concedidas a revistas especializadas, cuja análise foi aprofundada por meio de uma conversa virtual com a pesquisadora. Com suas pesquisas comparativas no Brasil, na França e no Japão, Hirata apresenta as diversidades e semelhanças dos mundos do trabalho, dos processos de globalização e seus efeitos, fortalecendo a discussão sobre a ampliação do conceito de trabalho - para além do trabalho assalariado - e sua centralidade. Seus estudos enriquecem o debate sobre a indissociabilidade entre as relações sociais de sexo/gênero e a divisão sexual do trabalho. A imbricação e a interdependência do conjunto das relações sociais figurarão de forma exemplar em suas análises acerca do trabalho de cuidado, possibilitando a condensação de ideias e conceitos. Dessa forma, a produção intelectual de Hirata, ao afirmar a transversalidade das relações sociais de sexo/gênero, subsidia reflexões sobre a determinação do processo saúde-doença, contribuindo decisivamente para os estudos da relação saúde e trabalho.

PALAVRAS-CHAVE Feminismo. Saúde. Trabalho. Saúde do trabalhador.

1 Fundação Oswaldo Cruz (Fiocruz), Escola Nacional de Saúde Pública Sergio Arouca (Ensp), Centro de Estudos da Saúde do Trabalhador e Ecologia Humana (Cesth) - Rio de Janeiro (RJ), Brasil sssoliver@gmail.com

2 Universidade Federal Fluminense (UFF), Instituto de Psicologia - Niterói (RJ), Brasil.

${ }^{3}$ Fundação Oswaldo Cruz (Fiocruz), Instituto Oswaldo Cruz (IOC),

Laboratório de Educação em Ambiente e Saúde - Rio de Janeiro (RJ), Brasil

\begin{abstract}
The article aims to reflect on the intellectual production of researcher Helena Hirata, as an important reference for the field of collective health, especially for understanding the relationships between work and the dynamics that involve health. Her theoretical-academic publications and interviews with specialized journals were used, whose analysis was deepened through a virtual conversation with the researcher. With her comparative research in Brazil, France, and Japan, Hirata presents the diversities and similarities of the worlds of work, the processes of globalization and their effects, strengthening the discussion about the expansion of the concept of work - beyond wage labor - and its centrality. Her studies enrich the debate on the inseparability between the social relations of sex/gender and the sexual division oflabor. The imbrication and interdependence of the set of social relations will appear in an exemplary way in her analysis of care work, enabling the condensation of ideas and concepts. In this way, Hirata's intellectual production, when affirming the transversality of the social relations of sex / gender, subsidizes reflections on the determination of the health-disease process, contributing decisively to the studies of the health-work relationship.
\end{abstract}

KEYWORDS Feminism. Health. Work. Worker's health. 


\section{Introdução}

Em um incomum tríplice arranjo, como um ikebana (arranjo de flores japonês), Helena Hirata conjuga técnica/disciplina, equilíbrio/ harmonia e sensibilidade/cuidado, conformando uma robusta e delicada trajetória acadêmica. $O$ presente artigo visa contribuir com a reflexão acerca da fecundidade de sua produção intelectual para a construção de perspectivas de análise das relações entre o trabalhar e as dinâmicas que envolvem a saúde, à medida que incorporam a questão das relações sociais de sexo/gênero.

Tal proposição decorre da importância de contribuições teóricas da autora, diretora de pesquisa emérita do Centro Nacional de Pesquisa Científica (CNRS) e pesquisadora colaboradora do Departamento de Sociologia da Universidade de São Paulo (USP), cujos temas da sociologia do trabalho - centralidade do trabalho, divisão internacional do trabalho, globalização, reestruturação produtiva e organizacional, com seus efeitos nas relações de trabalho - são discutidos a partir da perspectiva das relações sociais de sexo/gênero e da problematização da divisão sexual do trabalho, subsidiando reflexões acerca da determinação do processo saúde-doença.

Para desenvolvimento deste estudo, recorremos a uma diversidade de informações, proveniente de diferentes fontes, tais como: levantamento documental; produção teórico-acadêmica; entrevistas de Hirata concedidas a revistas especializadas e outras disponíveis na mídia. Além disso, merecem destaque os contatos realizados por e-mail e conversa virtual com a autora. Dessa forma, buscou-se, neste ensaio, efetuar uma discussão do conjunto de materiais, ressaltando conceitos, categorias e algumas das reflexões teóricas empreendidas pela pesquisadora e colocadas como ferramentas para o desenvolvimento de pesquisas, com vistas a apontar suas contribuições fundamentais para compreender-transformar os modos de vida, saúde e trabalho. Entendemos que a discussão em torno de suas ideias poderá gerar um terreno propício para que a temática de gênero seja mais bem apropriada nas pesquisas e intervenções pertinentes à saúde coletiva, em particular aquelas desenvolvidas no campo da saúde do trabalhador, assim como em outras áreas afins.

Nesse sentido, efetuamos uma análise que apreende a interface 'saúde e trabalho' de modo complexo, exigindo uma abordagem interdisciplinar ${ }^{\mathbf{1}}$. Ou seja, trata-se de um recorte permeado pela 'lente' desse universo de atuação e por experiências de pesquisas prévias por nós desenvolvidas, nas quais buscamos incorporar a dimensão das relações sociais de sexo/gênero teórica e metodologicamente. Assim, após apresentar dados acerca da biografia e dos focos investigativos de Hirata, nos debruçaremos sobre determinadas questões presentes em sua obra, especialmente relevantes, a nosso ver, para os estudos da saúde dos trabalhadores e trabalhadoras.

\section{Breve biografia, trajetória intelectual e construção de redes de trabalho}

Com base em conversa virtual realizada com a autora, assim como entrevistas concedidas e publicadas em revistas especializadas, apresentamos breve biografia de Helena Sumiko Hirata. Nascida no Japão, em 1946, lá viveu até 1952, quando, aos 5 anos de idade, seu pai decidiu retornar ao Brasil. Brasileira por opção, já que, aos 18 anos, precisou escolher entre a nacionalidade japonesa e a brasileira, reside, desde 1971, em Paris, na França, onde se tornou, em 1980, pesquisadora do CNRS.

Helena Hirata elegeu, desde jovem, o caminho da militância política. Sua ativa participação no movimento estudantil a levou a sair do Brasil, refugiando-se na França. Em plena ditadura cívico-militar, formou-se em filosofia na USP, associando-se a organizações de esquerda. Em 1968, tendo participado, em Ibiúna, no estado de São Paulo, do Encontro Nacional 
da União Nacional dos Estudantes (UNE), então na clandestinidade, permaneceu detida por dez dias. Devido à sua atuação política, foi obrigada a deixar o País sem concluir sua formação acadêmica. Portando documentos falsos, seguiu via Chile em direção à França, país onde encontraria seu companheiro e berço da produção intelectual que subsidiava até então os seus estudos.

Sem comprovar titulação acadêmica, inscreveu-se na Universidade Vincennes-SaintDenis-Paris VIII. Seu trabalho 'O papel do Estado nos países subdesenvolvidos: o caso do Brasil' conferiu-lhe, em 1979, o título correspondente atualmente ao de doutora. A tese, no campo da sociologia política, foi sua única pesquisa não empírica, elaborada a partir dos livros de Sérgio Buarque de Holanda.

Assim que conseguiu inserir-se no CNRS como datilógrafa (1977 a 1979), Hirata passou a contar com a solidariedade das demais mulheres, sociólogas - entre elas, Danièle Kergoat -, que a orientaram, inclusive, na elaboração de um projeto de pesquisa. Esse apoio foi essencial para que ela, futuramente, alcançasse uma vaga de pesquisadora na instituição. $\mathrm{O}$ movimento sindical para a integração dos 'hors-statuts' (com contratos de pesquisa, sem vínculo regular) foi fundamental para o seu ingresso no CNRS e de muitas de suas colegas por volta de 1980 .

Decidida, ainda, a continuar estudando o Brasil, conversou com o diretor do Centro de Sociologia das Organizações (CSO), Michel Crozier. Partiu dele a sugestão de um tema que aludisse ao Japão. Foi com o projeto 'Aspectos técnicos e socioculturais da organização do trabalho: comparação Brasil, França e Japão' que Helena Hirata passou a integrar, como pesquisadora, o CNRS, onde permanece desde janeiro de 1980.

Apesar de esse projeto inicial não contemplar questões vinculadas às relações de sexo/ gênero, a aproximação com Danièle Kergoat, em um sublaboratório do CSO, que se transformaria mais tarde no Grupo de Estudos sobre a Divisão Social e Sexual do Trabalho
(GEDISST), conduziu Hirata a estudar as diferenças entre homens e mulheres na organização do trabalho, nos salários, na promoção, na carreira. Assim, pôde evidenciar que as questões de gênero perpassavam o processo produtivo, as políticas de gestão e a dimensão tecnológica, levando à conclusão de que caberiam estudos específicos acerca de tal problemática. De 1992 a 1995, o GEDISST esteve sob a sua direção.

Em 1997, ela obteve a habilitação para dirigir pesquisas, que é a titulação de mais alto nível acadêmico na França, pela Universidade de Versailles-Saint-Quentin-en-Yvelines. Além disso, desde 2003, atua como diretora de pesquisa no CNRS, vinculada ao Grupo de Pesquisas Sociológicas e Políticas de Paris (CRESPPA), associado às Universidades de Paris VIII-Saint-Denis e Paris X-Nanterre. No CRESPPA, integra a equipe Gênero, Trabalho, Mobilidades (GTM). É diretora de pesquisa emérita desde sua aposentadoria, em 2011.

Os(as) pesquisadores(as) do CNRS foram, ao longo dos anos, assimilando atividades docentes, o que possibilitou a Helena Hirata orientar diversas teses de doutorado e pós-doutorado, inclusive de várias pesquisadoras brasileiras. Vale destacar que, segundo a autora, mesmo com o reconhecimento das pesquisadoras do CNRS do trabalho por elas desenvolvido, havia uma discriminação na própria instituição acerca da promoção à direção de pesquisa para as mulheres que trabalhavam com as temáticas do feminismo e das relações sociais de sexo/gênero.

Com a integração ao CNRS, Hirata dedicou-se durante décadas ao exame dos processos de globalização e de reestruturação produtiva, à observação da divisão sexual do trabalho e à análise do fenômeno do desemprego, chamando atenção para seus efeitos na saúde dos trabalhadores e das trabalhadoras - estudos e interlocuções desenvolvidos em momentos diversos com outros(as) pesquisadores(as), de diferentes disciplinas, entre eles(as), Danièle Kergoat, John Humphrey, Philippe Zarifian, Christophe Dejours, Kurumi Sugita, Nadya 
Araujo Guimarães, Alice Rangel de Paiva Abreu, Bila Sorj, Liliana Segnini e Pascale Molinier. Helena Hirata tem realizado investigações sempre em uma perspectiva comparativa entre os aspectos técnicos, sociais e culturais da organização do trabalho industrial; e, mais recentemente, esses estudos têm discorrido sobre o trabalho de cuidado na França, no Japão e no Brasil. Assim, a pesquisadora manteve seu vínculo com o país que a adotou desde o início de sua formação acadêmica até os dias atuais, incluindo o período em que esteve exilada.

Ao Brasil, somente retornara em 1979, após a Lei de Anistia aos presos e perseguidos políticos, promulgada em decorrência de uma ampla mobilização social. A partir de então, participou de inúmeros seminários, congressos e colóquios nacionais, além de ter estabelecido parcerias, inclusive institucionais, duradouras, integrando diversas redes de intercâmbio e de pesquisas. Atuou, principalmente, como pesquisadora visitante do Centro Brasileiro de Análise e Planejamento (Cebrap) e como professora visitante da USP e da Universidade de Campinas (Unicamp), sobretudo nos anos 1980-1990.

Cabe destacar ainda seu diálogo contínuo e permanente com movimentos sociais, sindicatos e grupos feministas no País. No dossiê organizado por Briguglio, Grecco, Lindôso e Lapa ${ }^{2}$, no qual é destacada a potente parceria construída entre Daniéle Kergoat e Helena Hirata, pode-se identificar como suas contribuições teóricas se constituíram e se constituem em um dos pilares de sustentação de certas experiências do movimento de mulheres brasileiro ${ }^{3}$.

Por fim, vale destacar que, em janeiro de 2020, realizou-se, em Paris, o colóquio 'Em torno do trabalho de Helena Hirata. Trabalho, gênero e subjetividades - da fábrica ao trabalho de cuidado', que contou com a participação de pesquisadores(as) e parceiros(as) da pesquisadora, procedentes da França, do Reino Unido, da Espanha, da Itália, do Japão, do Canadá, da Argentina e do Brasil.

A autora sempre valorizou a potência do trabalho coletivo, fosse nos projetos de pesquisas e nas cooperações internacionais, fosse na confecção de artigos e livros, fomentando uma sólida e instigante produção acadêmica. Várias dessas obras foram traduzidas em diversas línguas. Apresentamos as principais obras produzidas por Helena Hirata, sozinha ou em coautoria (quadro 1), e as entrevistas concedidas a revistas especializadas e outros canais midiáticos, bem como as participações da pesquisadora em podcasts, entre os anos 2000 e 2020 (quadro 2), nas quais resgata a sua trajetória intelectual e socioprofissional, além de discorrer sobre temas e objetos da sociologia do trabalho e das relações sociais de sexo/gênero, principalmente na França e no Brasil.

Quadro 1. Listagem de livros e coletâneas escritos ou organizados por Helena Hirata, entre os anos 1993 e 2017

\begin{tabular}{|c|c|c|c|c|}
\hline Título & Organizadores & Editora & Ano & Paginação \\
\hline Sobre o "modelo" japonês & Helena Hirata & São Paulo: EDUSP & 1993 & 1. ed./312p. \\
\hline $\begin{array}{l}\text { Nova divisão sexual do trabalho? Um olhar } \\
\text { voltado para a empresa e a sociedade }\end{array}$ & Helena Hirata & $\begin{array}{l}\text { São Paulo: Boi- } \\
\text { tempo }\end{array}$ & 2002 & 1. ed./336p. \\
\hline $\begin{array}{l}\text { Novas fronteiras da desigualdade: homens } \\
\text { e mulheres no mercado de trabalho }\end{array}$ & $\begin{array}{l}\text { Helena Hirata e Margaret } \\
\text { Maruani }\end{array}$ & São Paulo: SENAC & 2003 & 1.ed./365p. \\
\hline $\begin{array}{l}\text { Desemprego: trajetórias, identidades e } \\
\text { mobilização }\end{array}$ & $\begin{array}{l}\text { Helena Hirata e Nadya } \\
\text { Araujo Guimarães }\end{array}$ & São Paulo: SENAC & 2006 & 1. ed./320p. \\
\hline $\begin{array}{l}\text { Etrechômeur à Paris, São Paulo, Tokyo. Une } \\
\text { méthode de comparaison international }\end{array}$ & $\begin{array}{l}\text { Didier Demazière, Nadya } \\
\text { Araujo Guimaraes, Hele- } \\
\text { na Hirata e Kurumi Sugita }\end{array}$ & $\begin{array}{l}\text { Paris: Presses de } \\
\text { Sciences Po }\end{array}$ & 2013 & 1. ed./351p. \\
\hline
\end{tabular}


Quadro 1. (cont.)

\begin{tabular}{|c|c|c|c|c|}
\hline Título & Organizadores & Editora & Ano & Paginação \\
\hline $\begin{array}{l}\text { Marché du travail et genre. Regards croisés. } \\
\text { France Europe-Amérique Latine }\end{array}$ & $\begin{array}{l}\text { Helena Hirata, Margaret } \\
\text { Maruani e Maria Rosa } \\
\text { Lombardi }\end{array}$ & $\begin{array}{l}\text { Paris: La Décou- } \\
\text { verte }\end{array}$ & 2008 & 1. ed./278p. \\
\hline $\begin{array}{l}\text { Mercado de trabalho e gênero. Compara- } \\
\text { ções internacionais }\end{array}$ & $\begin{array}{l}\text { Helena Hirata, Albertina } \\
\text { de Oliveira Costa, Bila } \\
\text { Sorj e Cristina Bruschini }\end{array}$ & $\begin{array}{l}\text { Rio de Janeiro: Ed } \\
\text { FGV }\end{array}$ & 2008 & 1. ed./420p. \\
\hline Organização, trabalho e gênero & $\begin{array}{l}\text { Helena Hirata e Liliana } \\
\text { Segnini }\end{array}$ & São Paulo: SENAC & 2008 & 1. ed./360p. \\
\hline Dicionário crítico do feminismo & $\begin{array}{l}\text { Helena Hirata, Françoise } \\
\text { Laborie, Hélène Le Doaré } \\
\text { e Danièle Senotier }\end{array}$ & Editora UNESP & 2009 & 1. ed./342p. \\
\hline $\begin{array}{l}\text { Travail et rapports sociaux de sexe. Ren- } \\
\text { contres autour de Danièle Kergoat }\end{array}$ & $\begin{array}{l}\text { Helena Hirata, Xavier Du- } \\
\text { nezat, Jacqueline Heinen } \\
\text { e Roland Pfefferkorn }\end{array}$ & Paris: L'Harmattan & 2010 & 1. ed./277p. \\
\hline Le sexe de la mondialisation & $\begin{array}{l}\text { Helena Hirata, Jules } \\
\text { Falquet, Danièle Kergoat, } \\
\text { Brahim Labari, Nicky Le } \\
\text { Feuvre e Fatou Sow }\end{array}$ & $\begin{array}{l}\text { Paris: Presses de } \\
\text { Sciences Politiques }\end{array}$ & 2010 & 1. ed./278p. \\
\hline $\begin{array}{l}\text { Trabalho flexível, empregos precários? Uma } \\
\text { comparação Brasil, França, Japão. }\end{array}$ & $\begin{array}{l}\text { Helena Hirata, Nadya } \\
\text { Araújo Guimarães e } \\
\text { Kurumi Sugita }\end{array}$ & São Paulo: EDUSP & 2010 & 1. ed./344p. \\
\hline $\begin{array}{l}\text { Cuidado e cuidadoras. As várias faces do } \\
\text { trabalho do care }\end{array}$ & $\begin{array}{l}\text { Helena Hiratan e Nadya } \\
\text { Araujo Guimarães }\end{array}$ & São Paulo: ATLAS & 2012 & 1. ed./236p. \\
\hline $\begin{array}{l}\text { Gênero e trabalho no Brasil e na França. } \\
\text { Perspectivas interseccionais }\end{array}$ & $\begin{array}{l}\text { Helena Hirata, Alice } \\
\text { Rangel de Paiva Abreu e } \\
\text { Maria Rosa Lombardi }\end{array}$ & $\begin{array}{l}\text { São Paulo: Boi- } \\
\text { tempo. }\end{array}$ & 2016 & 1. ed./288p. \\
\hline $\begin{array}{l}\text { Le travail entre public, privé et intime. } \\
\text { Comparaisons et enjeux internationaux } \\
\text { du care }\end{array}$ & $\begin{array}{l}\text { Helena Hirata, Aurélie } \\
\text { Damamme e Pascale } \\
\text { Molinier }\end{array}$ & $\begin{array}{l}\text { Paris: Editions } \\
\text { L'Harmattan }\end{array}$ & 2017 & 1. ed./254p. \\
\hline El cuidado en América Latina & $\begin{array}{l}\text { Nadya Araujo Guimaraes } \\
\text { e Helena Hirata, }\end{array}$ & $\begin{array}{l}\text { Buenos Aires: Fun- } \\
\text { dación Medifé }\end{array}$ & 2020 & 1. ed./255p. \\
\hline
\end{tabular}

Fonte: Elaboração própria.

Quadro 2. Entrevistas publicadas sobre Helena Hirata, entre os anos 2000 e 2020

\begin{tabular}{|c|c|c|c|c|}
\hline Título & $\begin{array}{l}\text { Revista / Livro / } \\
\text { Canal }\end{array}$ & Entrevistadores/as & Ano & $\begin{array}{l}\text { Número / } \\
\text { Paginação }\end{array}$ \\
\hline $\begin{array}{l}\mathrm{O}(\mathrm{s}) \text { mundo(s) do trabalho e } \\
\text { seus dilemas sociais }\end{array}$ & Revista Plural & $\begin{array}{l}\text { Gisela Lobo Tartuce; João } \\
\text { Carlos Cândido; José Fran- } \\
\text { cisco Greco Martins; Marta } \\
\text { de Aguiar Bergamin }\end{array}$ & 2000 & no 7, p. $81-110$ \\
\hline Entrevista & $\begin{array}{l}\text { Trabalho, Educação e } \\
\text { Saúde }\end{array}$ & Revista & 2006 & $\begin{array}{l}\text { v. 4, no 1,p. } \\
\text { 199-203 }\end{array}$ \\
\hline O Japão que nasce no Brasil & De sol a sol & Fernando Portela & 2008 & p. $87-100$ \\
\hline $\begin{array}{l}\text { L'art de l'enquête collective sur } \\
\text { la division sociale et sexuelle } \\
\text { du travail }\end{array}$ & Mouvements & $\begin{array}{l}\text { Catherine Achin, Jim Cohen } \\
\text { e Virginie Descoutures }\end{array}$ & 2013 & $\begin{array}{l}\text { no } 76, \text { p. 138- } \\
152\end{array}$ \\
\hline
\end{tabular}


Quadro 2. (cont.)

\begin{tabular}{|c|c|c|c|c|}
\hline Título & $\begin{array}{l}\text { Revista / Livro / } \\
\text { Canal }\end{array}$ & Entrevistadores/as & Ano & $\begin{array}{l}\text { Número / } \\
\text { Paginação }\end{array}$ \\
\hline $\begin{array}{l}\text { Feminismos e Maternidade: } \\
\text { entrevista com Helena Hirata }\end{array}$ & $\begin{array}{l}\text { Carolina Pombo Com } \\
\text { a cabeça fora d'água } \\
\text { (canal do YouTube) }\end{array}$ & Carolina Pombo & 2014 & 29 min (vídeo) \\
\hline $\begin{array}{l}\text { Mulheres são mais qualifica- } \\
\text { das, mas o salário continua } \\
\text { paradoxal }\end{array}$ & Folha de Pernambuco & Rodrigo Passos & $26 / 04 / 2015$ & \\
\hline $\begin{array}{l}\text { Precarização afeta mais as } \\
\text { mulheres }\end{array}$ & Valor Econômico & Jorge Felix & 08/07/2016 & \\
\hline Entrevista & $\begin{array}{l}\text { Idéias Revista do } \\
\text { IFCH/UNICAMP }\end{array}$ & $\begin{array}{l}\text { Barbara Castro e Mariana } \\
\text { Roncato }\end{array}$ & 2016 & $\begin{array}{l}\text { v. 7, no } 1 p . \\
295-318\end{array}$ \\
\hline Entrevista & $\begin{array}{l}\text { RFI Brasil (Radio } \\
\text { France Internatio- } \\
\text { nale) }\end{array}$ & Maria Emilia Alencar & 2016 & \\
\hline $\begin{array}{l}\text { Série "Supermulheres": Mu- } \\
\text { Iher no mercado de trabalho: } \\
\text { desigualdades de gênero no } \\
\text { mercado de trabalho }\end{array}$ & $\begin{array}{l}\text { Mulheres de luta (ca- } \\
\text { nal do YouTube) }\end{array}$ & Canal Curta & 2016 & 3 min (vídeo) \\
\hline $\begin{array}{l}\text { Série "Supermulheres": Mu- } \\
\text { Iher no mercado de trabalho: } \\
\text { cargos e salários }\end{array}$ & $\begin{array}{l}\text { Mulheres de luta (ca- } \\
\text { nal do YouTube) }\end{array}$ & Canal Curta & 2016 & 3 min (vídeo) \\
\hline $\begin{array}{l}\text { Mulher no mercado de traba- } \\
\text { Iho: Livro: Gênero e Trabalho } \\
\text { no Brasil e na França }\end{array}$ & $\begin{array}{l}\text { Mulheres de luta (ca- } \\
\text { nal do YouTube) }\end{array}$ & Canal Curta & 2016 & 3 min (vídeo) \\
\hline $\begin{array}{l}\text { Helena Hirata: Trajetória } \\
\text { intelectual no feminismo } \\
\text { materialista }\end{array}$ & $\begin{array}{l}\text { TV Boitempo (canal } \\
\text { do YouTube) }\end{array}$ & Cebrap & 2016 & 45 min (vídeo) \\
\hline $\begin{array}{l}\text { Trabalho (imaterial), valor e } \\
\text { Classes Sociais: Diálogos com } \\
\text { pesquisadores contemporâ- } \\
\text { neos }\end{array}$ & $\begin{array}{l}\text { São Carlos: EdU- } \\
\text { FSCar }\end{array}$ & $\begin{array}{l}\text { São Carlos: EdUFSCar (H. } \\
\text { Amorim) }\end{array}$ & 2017 & p. $127-138$ \\
\hline Entrevista & $\begin{array}{l}\text { Revista Trabalho, } \\
\text { Educação e Saúde }\end{array}$ & $\begin{array}{l}\text { Daniel Groisman e Rachel } \\
\text { Gouveia Passos }\end{array}$ & 2019 & v. $17, n=2$ \\
\hline Hora de (re)partir & $\begin{array}{l}\text { Podcast 'Cuidar, verbo } \\
\text { coletivo' }\end{array}$ & Regina Stela Corrêa Vieira & $12 / 072019$ & $\begin{array}{l}\text { 63:09 min } \\
\text { (áudio) }\end{array}$ \\
\hline $\begin{array}{l}\text { Uma trajetória nos estudos de } \\
\text { gênero e trabalho }\end{array}$ & Revista Plural v.26.1 & $\begin{array}{l}\text { Grupo de Gênero e Sexuali- } \\
\text { dade do PPGS/USP }\end{array}$ & 2019 & p. $11-32$ \\
\hline $\begin{array}{l}\text { Helena Hirata - Da divisão } \\
\text { sexual do trabalho aos estu- } \\
\text { dos sobre o cuidado }\end{array}$ & $\begin{array}{l}\text { Podcast 'Larvas incen- } \\
\text { diadas' }\end{array}$ & Yumi Garcia dos Santos & 14/07 2020 & 43 min (áudio) \\
\hline $\begin{array}{l}\text { Trabalho e cuidado em tem- } \\
\text { pos de pandemia - entrevista } \\
\text { com Helena Hirata (CNRS, } \\
\text { França/USP) }\end{array}$ & $\begin{array}{l}\text { Centro de Estudos } \\
\text { Avançados CEA } \\
\text { - UFRRJ (canal do } \\
\text { YouTube) }\end{array}$ & $\begin{array}{l}\text { Centro de Estudos Avança- } \\
\text { dos CEA - UFRRJ }\end{array}$ & 05/08 2020 & $\begin{array}{l}\text { 1:30 horas } \\
\text { (vídeo) }\end{array}$ \\
\hline
\end{tabular}

Fonte: Elaboração própria. 


\section{Questões para compreender-transformar os modos de vida, saúde e trabalho}

Em suas análises sobre os mundos do trabalho, sob a perspectiva da divisão social e sexual do trabalho, Helena Hirata contribuiu de forma decisiva, desde os anos 1980, para aprofundar o debate sobre o conceito de trabalho e difundi-lo no meio acadêmico. A nosso ver, este debate tem implicações importantes para a compreensão das relações entre o trabalhar e as dinâmicas que envolvem a saúde, conforme indicaremos adiante.

\section{A centralidade e ampliação do conceito de trabalho: para além do trabalho assalariado}

Ao longo de sua densa e profícua produção intelectual, Hirata apresenta uma discussão a propósito das limitações de concepções teóricas bastante disseminadas pela sociologia do trabalho. A noção moderna de trabalho é fortemente vinculada à teorização da economia política, criticada nos efervescentes debates dos anos 1970. Em que pese o mérito de avançar na definição de trabalho assalariado, tal concepção apresenta limites para tratar adequadamente as distintas formas de trabalho não assalariado, pois apresenta o modelo masculino de trabalho como universal e não contempla as relações sociais de sexo/ gênero ${ }^{4,5}$. É uma concepção que caracteriza o trabalho como atividade social mensurável e passível de ser objetivada - uma vez que valoriza a apropriação do tempo do assalariado pelo capitalista -, contrastando com o que caracteriza o trabalho doméstico $0^{6}$. Ou seja, como é calcada na separação entre operações objetiváveis e o sujeito que as realiza, por intermédio do tempo, essa noção não contempla o trabalho doméstico - oriundo da disponibilidade histórica das mulheres em relação aos filhos e à vida conjugal - que é refratário à mensuração. Mesmo o cômputo do tempo dedicado ao trabalho doméstico não logra apreender a natureza do conjunto de ações envolvidas.

Assim, no bojo da proposta de ampliação do conceito de trabalho, está a recusa de compreender o trabalho como uma prática assexua$\mathrm{da}^{4,5,7-10}$, apontando para uma problematização da divisão sexual do trabalho. Trata-se de uma reconstrução do conceito, incluindo o trabalho profissional e doméstico, formal e informal, remunerado e não remunerado, pressuposto fundamental e fecundo para as pesquisas sobre o trabalho, os modos de vida e a saúde: produção e reprodução, classe social e sexo social (gênero) como categorias indissociáveis.

\footnotetext{
Para as mulheres, os limites temporais se dobram e multiplicam entre trabalho doméstico e profissional, opressão e exploração, se acumulam e articulam, e por isso elas estão em situação de questionar a separação entre as esferas da vida - privada, assalariada, política - que regem oficialmente a sociedade moderna6(254).
}

Vale aqui ressaltar duas marcas fundamentais dessa linhagem teórica, por meio das quais se pode identificar sua singularidade. A primeira refere-se à compreensão da centralidade do trabalho na vida das pessoas, em oposição aos teóricos que propagaram a tese do fim do valor trabalho, na década de 19906. A segunda marca é o entendimento de que a divisão sexual do trabalho e as relações sociais de sexo/gênero formam um sistema. Isso porque o trabalho é a base material da 'tensão' que se estabelece entre homens e mulheres, como grupos sociais ${ }^{4,5}$.

São inúmeros os dados empíricos que atestam o caráter indissociável do trabalho profissional e doméstico. A vinculação histórica das mulheres ao espaço doméstico, por si só, já as coloca em desvantagem em relação aos homens quanto às atividades que favorecem a promoção na carreira. Tal desvantagem permeia toda a vida profissional, inclusive a 
aposentadoria, posto que a descontinuidade da vida profissional e o trabalho em tempo parcial são mais comuns entre as mulheres ${ }^{11}$.

Não apenas as condições do exercício do trabalho profissional se articulam ao trabalho doméstico, o próprio "tempo do assalariamento é condicionado pelo tempo do trabalho doméstico"6(254). Os estudos dos usos do tempo são reveladores nesse contexto, pois, apesar de o intervalo de tempo que demarca um dia circunscrever-se a 24 horas para todos e todas, os modos como se dão os usos desse tempo traduzem as normas sociais de cada grupo. Ademais, a concepção de divisão sexual do trabalho influenciou sobremaneira iniciativas do Estado brasileiro como, por exemplo, as estatísticas oficiais do Instituto Brasileiro de Geografia e Estatística (IBGE) que levam em conta o tempo dedicado ao trabalho doméstico, além de estudo-piloto sobre o uso do tempo ${ }^{12}$. Outrossim, indicadores e diagnósticos mais precisos das desigualdades de gênero poderão subsidiar discussões sobre políticas públicas de criação de creches e locais de acolhimento a idosos, entre outros, no sentido de ampliar as possibilidades de autonomia profissional e pessoal das mulheres.

Ao associar as informações sobre o uso do tempo a dados qualitativos sobre o trabalho doméstico, Hirata11(16) observa que "é importante refletir sobre os afetos, que estão na base da reprodução da servidão doméstica". Considerando que o papel de único provedor já não é dominante - e, ainda assim, o trabalho doméstico é dividido de forma assimétrica -, ela se questiona, então, como os homens demonstrariam o seu amor.

\section{Consubstancialidade, coextensividade das relações sociais e produção globalizada}

A discussão sobre consubstancialidade, que aponta para a imbricação e a interdependência do conjunto das relações sociais - cada uma imprimindo suas marcas sobre as outras -, em Hirata e Kergoat ${ }^{\mathbf{1 3}}$ está ligada ao feminismo materialista, no qual o trabalho é central em sua materialidade, enquanto prática social, e se interessa pelas relações de poder, de exploração, de opressão e de dominação entre homens e mulheres.

$\mathrm{Na}$ atualidade, essa problematização ganha novos contornos, tendo em vista a teoria queer, o movimento LGBTQIA+, a discussão a propósito dos vários sexos, conforme destacou a pesquisadora, durante conversa virtual. Nas reflexões de Hirata ${ }^{14}$, o binômio trabalho-sexo é valorizado, assim como é fundamental a referência à divisão sexual do trabalho, profissional e doméstico, subjacente à divisão sexual do poder e do saber.

Essa perspectiva permite a crítica à teoria marxista das classes sociais, que não possibilita apreender o lugar das mulheres na produção e na reprodução social. Em associação com Kergoat, Hirata ${ }^{13-18}$ defende que as relações de classe são sexuadas e que as relações sociais de sexo/gênero e de classe organizam a totalidade das práticas sociais. Na conclusão dessas autoras, a formação social do patriarcado é inerente ao capitalismo. $\mathrm{O}$ que se tem é um capitalismo patriarcal.

Assim, a abordagem em termos de relações sociais de sexo/gênero indica que dominação, opressão e exploração estão presentes em todos os espaços sociais e se retroalimentam. Como afirma Kergoat ${ }^{9}$, uma relação social não pode ser um pouco mais vigorosa do que outra: ela é, ou não, uma relação social. Esse aspecto conduz à ideia de 'coextensividade' das relações sociais:

[...] a exploração por meio do trabalho assalariado e a exploração do feminino pelo masculino são indissociáveis, sendo a esfera da relação de classes aquela em que, simultaneamente, é exercido o poder dos homens sobre as mulheres ${ }^{8(277)}$.

Para compreender os antagonismos que se expressam nas relações sociais de sexo/ gênero, é preciso investigar como ocorre a divisão sexual do trabalho, cujos princípios 
organizadores são os da separação (há trabalhos de homens e trabalhos de mulheres) e de hierarquia (os trabalhos de homens têm mais valor que o de mulheres). Em que pesem esses princípios estarem presentes em todas as sociedades e serem legitimados pela ideologia naturalista, isso não significa, segundo Hirata e Kergoat ${ }^{5}$, que:

[...] a divisão sexual do trabalho seja um dado imutável. Ao contrário, ela tem inclusive uma incrível plasticidade: suas modalidades concretas variam grandemente no tempo e no espaço, como demonstraram fartamente antropólogos e historiadores(as). O que é estável não são as situações (que evoluem sempre), e sim a distância entre os grupos de sexo5(600).

Entre as mudanças e as permanências apontadas por Hirata nos modos de conciliação entre a vida familiar e a vida profissional, verifica-se a responsabilidade do trabalho doméstico ainda incidindo fortemente sobre as mulheres - quer pelo acúmulo, em que conciliam o trabalho profissional e o trabalho doméstico e de cuidados, quer pela delegação a outras mulheres do cuidado com a casa, com a família, com os idosos e com as crianças, em uma combinação de delegação e acúmulo que se distribui por uma rede de mulheres, ${ }^{4,5}$.

Uma importante reflexão proposta por Hirata, articulada à discussão sobre as mudanças e permanências da divisão sexual do trabalho, refere-se aos processos de produção globalizada. Suas pesquisas comparativas entre diferentes países permitiram que participasse ativamente, nos anos 1990, do debate em torno da globalização e da reestruturação produtiva ${ }^{19-22}$. Os processos de globalização são problematizados a partir de um olhar crítico e fundamentado pela abordagem das relações sociais de sexo/ gênero, permitindo a incorporação de novos elementos na análise das dinâmicas que afetam a vida e o trabalho das mulheres em âmbito mundial, com destaque para três de suas dimensões ${ }^{23}$.
Em primeiro lugar, as políticas neoliberais de desregulamentação do trabalho, somadas à externalização da produção, com as cadeias de subcontratação impondo ainda mais condições precárias de trabalho às mulheres. Por outro lado, as privatizações, ao reduzirem a oferta dos serviços públicos, ampliam a demanda pelo trabalho não remunerado das mulheres, assim como acarretam um aumento da inserção das trabalhadoras no mercado de trabalho remunerado, notadamente no setor de serviços. No entanto, os empregos criados são vulneráveis e precários, com o crescimento do trabalho informal nos países do Hemisfério Sul.

Em segundo lugar, o desenvolvimento das novas tecnologias de informação e de comunicação e a financeirização das economias propiciaram um aumento do assalariamento feminino no Hemisfério Sul (nos anos 1990), associado ao crescimento de algumas atividades em determinados setores, como o da informática e do telemarketing. Em seus estudos comparativos, Hirata evidencia que as condições de trabalho e de remuneração são claramente desfavoráveis nas filiais dos grupos internacionais situadas nos países do Sul.

Ademais, em terceiro lugar, a globalização acarretou mudanças na atuação dos organismos internacionais com relação às políticas de igualdade entre homens e mulheres, paralelamente à regulação dos estados nações e das empresas multinacionais, políticas generalizantes que desconsideram as singularidades locais, muitas vezes tendo consequências inversas às esperadas ${ }^{\mathbf{2 2 , 2 3}}$.

A imbricação das relações de sexo e de classe é o que define inicialmente o conceito de consubstancialidade. Posteriormente, esse conceito irá se consolidar em torno de três relações sociais fundamentais: classe, gênero e raça, o que se mostrará de forma exemplar, nas reflexões acerca do trabalho de cuidado globalizado, conforme veremos adiante. $\mathrm{O}$ debate em torno das perspectivas teóricas da interseccionalidade ou da consubstancialida-

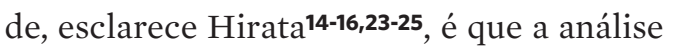
interseccional evidencia mais, em geral, o par 
gênero-raça, deixando a dimensão classe social em um plano menos visível. A não hierarquização, a interseccionalidade das três dimensões, de acordo coma autora, pode "ser considerada um instrumento de conhecimento e ao mesmo tempo um instrumento de ação política"24(61).

\section{Subjetividade e trabalho}

É importante registrar o interesse de Hirata pela questão da subjetividade e a adoção de uma perspectiva interdisciplinar no desenvolvimento de suas pesquisas $\mathbf{4 , 7 7 , 1 8 , 2 6}$. A problemática do individual e do coletivo mobilizou a autora, desde suas primeiras incursões, por razões de ordem teórica e empírica. Do ponto de vista teórico, a relação interindividual homem/mulher se constitui como um dos componentes do antagonismo entre os grupos sociais que é notabilizado pela abordagem das relações sociais de sexo/gênero. Já os materiais empíricos de uma pesquisa de campo realizada por ela no Japão, ainda no início da década de 1980, despertaram a necessidade de uma análise sobre a relação entre o individual, o grupo e o coletivo. No caso, a observação de que havia uma primazia do grupo sobre o indivíduo mostrou-se como um ponto fundamental a ser elucidado, tendo em vista a compreensão da dinâmica do trabalho industrial no País.

De acordo com Hirata ${ }^{22}$, no tocante ao processo de trabalho, o capitalismo japonês mobilizava especificamente o sujeito desse processo, e não uma 'força de trabalho' ou uma força de trabalho homogênea e quantificável. Os resultados de sua pesquisa indicaram que as relações sociais, especialmente as relações homem-mulher, são essenciais para a análise do desempenho da indústria japonesa. Nos estudos comparativos internacionais, a integração do contexto social às relações sociais de sexo/gênero - com sua dimensão intersubjetiva - possibilitou, assim, tanto a crítica aos determinismos econômicos e tecnológicos, como a crítica ao culturalismo ${ }^{\mathbf{1 8 , 2 2 , 2 3}}$. Ainda em 1981, um estudo sobre desemprego realizado com John Humphrey, em um bairro da classe operária de São Paulo, levou à compreensão de que uma análise a partir do ponto de vista da divisão sexual do trabalho demanda a convocação de diferentes e complementares teorias: dos mercados de trabalho, dos processos de trabalho e do sujeito-sexuado.

O diálogo com a psicodinâmica do trabalho, a partir de 1987, insere-se exatamente nessa perspectiva. Hirata sinaliza que, tanto para a abordagem das relações sociais de sexo/gênero quanto para a psicodinâmica do trabalho, as relações de trabalho não são apenas relações de exploração, mas também relações intersubjetivas. Como uma das clínicas do trabalho, a psicodinâmica do trabalho ${ }^{27}$ tem o olhar dirigido para as relações intersubjetivas, cujo enfoque é considerado fundamental para a análise do trabalho e para o campo da saúde mental e trabalho. Uma importante contribuição de Hirata, em parceria com Kergoat ${ }^{26}$, para o desenvolvimento dessa abordagem foi abrir uma discussão a respeito da ausência da dimensão sexuada da divisão do trabalho em suas construções teóricas sobre sofrimento e prazer no trabalho, além do debate em torno dos sistemas defensivos desenvolvidos coletivamente diante de situações potencialmente nocivas à saúde mental.

Apesar de seus valiosos instrumentos conceituais, estes não consideravam, até então, a relação de poder existente entre os sexos nem a correspondência de uma ética e uma estética da abnegação e do altruísmo feminina a uma ética e uma estética da virilidade masculina, historicamente exercícios de subjetividade que são explorados pela organização do trabalho e que, por sua vez, também podem estar na base dos sistemas defensivos apregoados por aquela abordagem. Essa crítica gerou o encaminhamento de vários estudos posteriores, entre eles, o desenvolvido por Pascale Molinier27, com a criação de conceitos que buscam tratar das relações intersubjetivas no trabalho, tendo em vista as vivências das trabalhadoras e dos trabalhadores, com suas especificidades.

Dessa forma, o exame dos elementos subjetivos - não econômicos e não tecnológicos 
- do desempenho e da produtividade das organizações envolve a teorização a respeito do individual e do coletivo, acerca do trabalho e da subjetividade e com relação às dimensões éticas e de sofrimento e prazer no/do trabalho.

\section{Estratégias metodológicas e seus desdobramentos teóricos}

Durante conversa realizada com a pesquisadora, foi mencionado que, no campo da sociologia, a comparação internacional é uma das maneiras de aceder a um conhecimento novo. Dessa forma, as diversas pesquisas comparativas de Helena Hirata desenvolvidas desde os anos 1980, no Brasil, na França e no Japão, permitiram dois enfrentamentos importantes. Em primeiro lugar, ao sempre priorizar o trabalho de campo, tendo como premissa um ponto de vista situado, atenta à experiência das relações de poder, a autora evitou que as relações sociais de sexo/gênero sofressem um 'apagamento' em face das relações de classe e viabilizou as bases para a consolidação de uma epistemologia feminista, principalmente do feminismo materialista, unindo-se às principais pensadoras dessa vertente. Em segundo lugar, suas pesquisas permitiram a comparação entre diversidades e semelhanças nos mundos do trabalho, bem como o registro de seus processos de globalização e seus efeitos.

Hirata também destacou que suas pesquisas são empreendidas de forma artesanal, fazendo uso de roteiros bastante flexíveis para a realização de entrevistas semiestruturadas, em geral feitas individualmente. Ressaltou ainda a importância de entrevistar os mais diversos sujeitos sempre em sua língua materna, ou seja, em francês, em japonês ou em português, além de, e fundamentalmente, interagir de maneira pessoal com os(as) entrevistados(as), deixando-se afetar por suas problemáticas. Essas entrevistas, realizadas com grande número de sujeitos, durante um período prolongado, permitem a produção de materiais riquíssimos, que contemplam um olhar sobre as diferentes e indissociáveis esferas de vida.
Conforme podemos perceber, cada trabalho de campo proposto configura-se como uma verdadeira imersão no mundo dos sujeitos entrevistados ${ }^{\mathbf{1 5}, 25}$.

Desse modo, Hirata ${ }^{19}$ percebeu que, se a divisão sexual do trabalho está persistentemente presente nos diferentes países, suas fronteiras se deslocam, gerando configurações diversas, que resultam, sobretudo, dos movimentos sociais e da potência de ação das mulheres. Como afirma:

Se o forte desenvolvimento das tecnologias domésticas tendeu a facilitar essas tarefas, a divisão sexual do trabalho doméstico e a atribuição deste último às mulheres, em realidade, continuou intacta. A relação entre o trabalho doméstico e a afetividade parece estar no centro dessa permanência19(150).

Por meio da associação de estudos de campo aprofundados a comparações sobre os diferentes cenários internacionais, as dinâmicas adjacentes à consubstancialidade podem ser identificadas com mais clareza pela autora $^{14-16}$, envolvendo questões de classe, sexo e raça. Ademais, a perspectiva interdisciplinar adotada por Hirata ${ }^{11,19}$ permite o acesso a problemas individuais e coletivos, que se referem ao trabalho de categorias profissionais específicas, articulando questões subjetivas, econômicas e políticas.

\section{O trabalho de cuidado: a condensação de ideias e conceitos}

As estratégias de pesquisa mobilizadas por Helena Hirata têm permitido, ainda, que sejam produzidos conhecimentos valiosos acerca da dimensão do cuidado em diversas atividades de trabalho, cuja importância e invisibilidade são indiscutíveis. Além do aspecto autobiográfico - envelhecimento da sua mãe e da perspectiva de aproximação do seu próprio envelhecer -, o interesse específico, desde 2009, pelo trabalho de cuidado pela pesquisadora deve-se, principalmente, ao fato de essa modalidade de 
trabalho sintetizar a indissociabilidade entre trabalho doméstico e profissional, abarcando um amplo espectro de atividades, remuneradas e não remuneradas, e diferentes setores (saúde, educação, assistência social, serviços de cuidadora). Outrossim, os estudos sobre o trabalho do cuidado são decisivos para as discussões referentes à consubstancialidade 13-15,23-25, evidenciando, de forma cabal, as desigualdades imbricadas das relações sociais de gênero, de classe e de raça.

O trabalho de cuidado, que não consiste apenas de uma postura de atenção, mas de um conjunto de atividades materiais e de relações que procuram responder concretamente às necessidades dos outros, vem sendo historicamente exercido por mulheres com idosos, crianças, doentes, pessoas com deficiência. Entretanto, o desenvolvimento das profissões voltadas para o cuidado, assim como a mercantilização e a externalização desse tipo de trabalho - fruto do envelhecimento populacional e da massiva inserção das mulheres no mercado de trabalho -, contribuiu para sua maior visibilização9. São ações exercidas pelas mulheres por muito tempo de forma gratuita e invisível, que finalmente ganham reconhecimento como trabalho, embora ainda pouco valorizado do ponto de vista salarial e social.

De acordo com os estudos comparativos e interdisciplinares desenvolvidos por Hirata ${ }^{14,15,22-25}$ no Brasil, na França e no Japão, os(as) cuidadores(as), tanto em domicílios como em instituições de longa permanência de idosos, são compostos(as), em sua maioria, por mulheres pobres, embora no Japão, nas instituições de longa permanência, haja quase $40 \%$ de cuidadores do sexo masculino. Tal percentual é devido a uma política governamental que, diante do cenário de grave crise financeira mundial em 2008, estimulou a formação e a garantia de emprego para esse contingente. Hirata destaca ainda que, no caso específico do Brasil e da França, a grande maioria do contingente feminino é de mulheres negras, muitas vezes provenientes de migração interna ou externa.
Nessa direção,

os fluxos migratórios e a globalização do cuidado e do trabalho reprodutivo desenham os contornos de uma nova divisão internacional do trabalho de serviço24(55).

É interessante destacar que uma nova divisão internacional do trabalho é vislumbrada, então, quando a dimensão étnico-racial é integrada à análise. O processo da repartição social do trabalho de cuidado, portanto, evidencia-se a partir da incorporação dessa dimensão na comparação entre os três países objetos da análise.

Na França (em Paris e Île-de-France), mais de $90 \%$ das cuidadoras são migrantes externas. Dessa forma, a especificidade do trabalho de cuidado é inegável: ele não pode ser deslocalizado, como ocorre com a produção industrial das multinacionais ${ }^{22}$. No Brasil, há uma migração interna: muitas mulheres do meio rural ou de cidades do interior, principalmente do Nordeste, trabalham como cuidadoras nas principais metrópoles. Tanto no Brasil quanto na França, as cuidadoras se autodeclaravam negras ou pardas e relataram situações constantes de racismo, seja por intermédio de violência verbal ou mediante comportamentos discriminatórios ${ }^{16,23,26}$.

As relações sociais se manifestam de formas diferenciadas nos três países, mas são sempre os mais vulneráveis que se tornam os provedores ou provedoras do cuidado. Desse modo, embora o perfil dos(as) cuidadores(as) entrevistados(as) seja bastante heterogêneo, há em comum o fato de essa ser uma profissão pouco valorizada. Nos três países, os salários são relativamente baixos e os(as) profissionais gozam de pouco reconhecimento social. A igualdade de condições profissionais, ante a desigualdade de perfis e trajetórias desses(as) trabalhadores(as), parece encontrar sua explicação no próprio cerne da atividade de cuidado, realizado tradicionalmente e gratuitamente, na esfera doméstica e familiar, pelas mulheres ${ }^{15,23,24,26}$.

Hirata ${ }^{25(27)}$ pôde, ainda, observar a diferença que cuidadores e cuidadoras fazem entre 'o que é cuidado' e 'em que consistem suas atividades' 
quanto aos beneficiários do serviço. Para ambos, há uma clara diferença entre provisão e práticas, entre ética e trabalho concreto. Para eles(as), as atividades realizadas referem-se não apenas à dimensão fisiológica, mas também à dimensão psicológica, e, entre as disposições apontadas como importantes, evoca-se a paciência necessária para realizar essas atividades. Entretanto, o 'cuidado' e as 'atividades' são percebidos como ‘ajuda' pelas cuidadoras e, menos frequentemente, pelos cuidadores.

Sob a ótica da demanda por cuidado, na França, o estado e as políticas públicas têm um papel essencial para supri-las. No Japão, a família apresenta-se como maior suporte de provisão de cuidados. Já no Brasil, as lacunas do Estado são compensadas por redes de apoio provenientes da vizinhança, principalmente de mulheres da família.

Esses estudos desenvolvidos por Helena Hirata 24(61-62) reafirmam, então, a importância do reconhecimento e da valorização do trabalho de cuidado, ainda mais visível com a demanda crescente por cuidado decorrente da expansão demográfica e do envelhecimento da população nas sociedades industriais e pós-industriais. Nessa direção, coloca que é inegável a relevância da

Discussão teórica em torno de 'desgenerizar' o care para pensar uma nova divisão sexual do trabalho de cuidado, em que homens e mulheres sejam responsáveis pela atenção às pessoas dependentes.

O cuidado deve ser realizado independentemente do sexo, já que todos e todas apresentarão, em algum momento de suas vidas, a condição de vulnerabilidade.

\section{Alguns diálogos com as pesquisas em saúde}

No que tange especificamente às contribuições de Hirata para o desenvolvimento de pesquisas na área da saúde coletiva, ressaltam-se, assim, as consequências incontornáveis do legado vinculado à afirmação da centralidade do trabalho, que é um dos pontos de destaque em sua obra, nos modos de apreensão de diferentes problemas. Nessa linha, com o entendimento de que as esferas da produção e da reprodução, de que o trabalho remunerado e o trabalho doméstico estão sempre em conexão, isso propicia a aquisição de um olhar mais abrangente (não fragmentado), beneficiando tanto os estudos que tratam da vida no âmbito familiar quanto aqueles que se debruçam sobre os mundos da produção. No primeiro caso, seria um equívoco desconsiderar a questão do trabalho e das relações de classe, por exemplo, em estudos sobre saúde e violência doméstica. No segundo caso, seria uma falha ignorar o problema da dominação, da opressão e da exploração das mulheres - e, mais especificamente, das mulheres negras. Observamos, também, que a perspectiva da divisão sexual do trabalho, além de conduzir a um questionamento das 'competências' requeridas às mulheres para atuar, principalmente, em trabalhos repetitivos e no setor de serviços, contribui para o reconhecimento de quadros diferenciados de sofrimento e de adoecimento de trabalhadores(as).

Encontramos, igualmente, inspiração em suas discussões sobre a globalização, tendo em vista a identificação de situações de maior vulnerabilidade social das mulheres em alguns países devido à dinâmica de interdependência das relações entre sexo/gênero, classe e raça. Além disso, na medida em que essas relações e a divisão do trabalho não são pensadas de forma determinista, considerando a existência de um espaço de liberdade para o exercício da capacidade de ação dos(as) explorados(as), oprimidos(as) e dominados(as), entendemos que estudos comparativos como os desenvolvidos por Helena Hirata são fundamentais para a elucidação das possibilidades e dos obstáculos encontrados em diferentes contextos para que as mudanças desejadas aconteçam.

Seu aporte mais recente às análises sobre o trabalho de cuidado dialoga de forma direta com grandes demandas das sociedades 
contemporâneas, em particular, a condição de maior longevidade, cujo preço é o investimento no cuidado das gerações de maior idade. Situações de emergência decorrentes do desequilíbrio ambiental e climático - fruto de ações humanas -, a exemplo de desastres, ou mesmo a atual pandemia de Covid-19, também se beneficiam de seus estudos, como podemos conferir na entrevista ao Centro de Estudos Avançados (CEA), da Universidade Federal Rural do Rio de Janeiro (UFRRJ), concedida em 5 de agosto de 2020. Nesta, as vivências dramáticas vinculadas ao trabalho profissional em home office e, principalmente, $\operatorname{dos}($ as) profissionais do cuidado e demais trabalhadores(as) que permaneceram na linha de frente, são debatidas de forma muito fecunda. Sua defesa da centralidade política e ética do cuidado na produção da vida e da saúde é notável.

No Brasil, o debate sobre a temática gênero, saúde e trabalho tem como marco dois eventos importantes, que contaram com a valiosa contribuição de Hirata. Em 1999, por ocasião do II Congresso Internacional Mulher, Trabalho e Saúde, realizado no Rio de Janeiro, ocorreu a conferência 'Trabalho: uma abordagem interdisciplinar', proferida pela pesquisadora. Em agosto de 2006, durante o VIII Congresso Brasileiro de Saúde Coletiva e XI Congresso Mundial de Saúde Pública, realizado também no Rio de Janeiro e promovido conjuntamente pela Associação Brasileira de Saúde Coletiva (Abrasco) e pela World Federation of Public Health Associations (WFPHA), a contribuição de Hirata como participante da mesa-redonda 'Trabalho, Saúde Coletiva e Globalização: quais possibilidades?' fomentou um debate sobre as desigualdades de gênero ante a internacionalização da economia, com base em suas pesquisas comparativas na França, no Brasil e no Japão.

O contato de diferentes grupos de investigação brasileiros realizados com Hirata foi crucial para o delineamento de linhas de pesquisa que visavam tecer reflexões compartilhadas sobre a temática 'saúde e trabalho', considerando a transversalidade das relações sociais de sexo/gênero. Uma dessas interlocuções resultou no desenvolvimento de projeto de cooperação internacional entre o CNRS e a Fundação Oswaldo Cruz (Fiocruz), no âmbito do Centro de Relações Internacionais em Saúde (Cris/Fiocruz).

Sua produção intelectual foi fundamental na construção de nossos olhares para as pesquisas sobre saúde e trabalho nos campos da educação, da saúde e do telemarketing ${ }^{\mathbf{1}, 28}$, entre outras. Os questionamentos propiciados por suas reflexões, conjugados à concepção de saúde com a qual nos alinha$\operatorname{mos}^{29}$, conduziram-nos ao entendimento de que a relação entre a saúde e o trabalho se estabelece de acordo com os 'modos sexuados de viver'30. Nessa linha, afirmamos que a atribuição das tarefas domésticas e de cuidado com os familiares às mulheres tem implicações em outras esferas da vida, de forma que o menor tempo disponível para si mesma "tende a resultar em menores possibilidades de negociação cotidiana pela saúde, levando a diferenciações atravessadas pelas questões de gênero"1(324).

\section{À guisa de conclusão}

Em sua trajetória interdisciplinar, Helena Hirata fez-se acompanhar de rigor teórico e profunda acuidade metodológica, permitindo análises que articulam questões subjetivas, econômicas e políticas pertinentes ao trabalho de mulheres e homens, de diferentes países e contextos sociais. Desde os embates teóricos sobre o conceito de trabalho, a ousadia de questionar princípios marxistas, até os estudos mais recentes sobre o trabalho de cuidado, pode-se vislumbrar uma linha de coerência que acompanha sua intensa atividade intelectual e comprometimento com os movimentos sociais.

Por fim, se buscarmos identificar um elemento que permeia a vasta obra de Hirata, um questionamento que lhe seja irresistível, uma interpretação da qual não abre mão, esse 
elemento se expressa nas desigualdades nos mundos do trabalho, nas diferenças injustas porque evitáveis, e evitáveis porque construídas pelo social. É este o esteio de sua obra, a linha-mestra que guia sua profícua contribuição às ciências humanas e à compreensão de grandes questões da contemporaneidade.

\section{Colaboradoras}

Oliveira SS (0000-0002-1477-749X)*, Neves MY (0000-0002-9821-3826)*, Brito JC (00000001-6744-4595)* e Rotenberg L (0000-00024132-2167)* contribuíram igualmente para a elaboração do manuscrito.

\section{Referências}

1. Brito JC, Neves MY, Oliveira SS, et al. Saúde, subjetividade e trabalho: o enfoque clínico e de gênero. Rev. bras. saúde ocup. 2012 [acesso em 2021 maio 19]; 37(126):316-329. Disponível em: http://dx.doi. org/10.1590/S0303-76572012000200013.

2. Briguglio B, Grecco FS, Lindôso RO, et al. Apresentação: As proposições teórico-metodológicas de Danièle Kergoat e Helena Hirata. Polít. Trab. 2021 [acesso em 2021 maio 19]; 1(53):12-21. Disponível em: https:// doi.org/10.22478/ufpb.1517-5901.2020vln53.57500.

3. Moreno R, Godinho T, Faria N. Trabalho como produção do viver: consequências políticas para o feminismo. Polít. Trab. 2021 [acesso em 2021 maio 19]; 1(53):129-143. Disponível em: https://doi. org/10.22478/ufpb.1517-5901.2020vln53.51440.

4. Hirata H, Kergoat D. A divisão sexual do trabalho revisitada. In: Maruani M, Hirata H, organizadoras. As novas fronteiras da desigualdade: homens e mulheres no mercado de trabalho. São Paulo: Senac; 2003. p. 111-123.

5. Hirata H, Kergoat D. Novas configurações da divisão sexual do trabalho. Cad. pesqui. 2007 [acesso em 2021 maio 19]; 37(132):595-609. Disponível em: https://doi. org/10.1590/S0100-15742007000300005.
6. Hirata H, Zarifian P. Trabalho (o conceito de). In: Hirata H, Laborie F, Doaré H, et al., organizadoras. Dicionário crítico do feminismo. São Paulo: Unesp; 2009. p. 251-255.

7. Hirata H. Divisão, relações sociais de sexo e do trabalho: contribuição à discussão sobre o conceito de trabalho. Em Aberto. 1995 [acesso em 2021 maio 19]; 15(65):39-49. Disponível em: http://www.emaberto. inep.gov.br/ojs3/index.php/emaberto/article/download/2316/2055.

8. Hirata H. Nova divisão sexual do trabalho? Um olhar voltado para a empresa e a sociedade. São Paulo: Boitempo; 2002.

9. Kergoat D. Em defesa de uma sociologia das relações sociais. Da análise crítica das categorias dominantes à elaboração de uma nova conceituação. In: Kartchevsky-Bulport A, Combes D, Haicault M, et al. O sexo do trabalho. Rio de Janeiro: Paz e Terra; 1986. p. 7993.

10. Kergoat D. Divisão sexual do trabalho e relações sociais de sexo. In: Hirata H, Laborie F, Doaré HL, et al., organizadoras. Dicionário crítico do feminismo. São Paulo: Unesp; 2009. p. 67-75.
* Orcid (Open Researcher and Contributor ID). 
11. Hirata H. Mudanças e permanências nas desigualdades de gênero: divisão sexual do trabalho numa perspectiva comparativa. São Paulo: Friedrich-Ebert-Stiftung Brasil; 2015. [acesso em 2021 maio 19]. Disponível em: https://library.fes.de/pdf-files/bueros/ brasilien/12133.pdf.

12. Bandeira LM, Preturlan RB. As pesquisas sobre uso do tempo e a promoção da igualdade de gênero no Brasil. In: Fontoura N, Araujo C, organizadoras. Uso do tempo e gênero. Rio de Janeiro: UERJ; 2016. p. 43-61.

13. Hirata H, Kergoat D. A classe operária tem dois sexos. Estud. fem. 1994 [acesso em 2021 maio 19]; 2(3):93100. Disponível em: https://doi.org/10.1590/\%25x.

14. Hirata H. Gênero, classe e raça: interseccionalidade e consubstancialidade das relações sociais. Tempo soc. 2014 [acesso em 2021 maio 19]; 26(1):61-73. Disponível em: https://doi.org/10.1590/ S0103-20702014000100005.

15. Hirata H. Mulheres brasileiras: relações de classe, de "raça" e de gênero no mundo do trabalho. Confins. 2016 [acesso em 2021 maio 19]; (26). Disponível em: https://doi.org/10.4000/confins.10754.

16. Hirata H. Gênero, patriarcado, trabalho e classe. Trab. neces. 2018 [acesso em 2021 maio 19]; 16(29):14-27. Disponível em: https://doi.org/10.22409/tn.16i29. p4552.

17. Hirata H. Centralidade do trabalho, subjetividade e relações sociais. Pesquisar com Danièle Kergoat. In: Kergoat D. Lutar, dizem elas... Recife: SOS Corpo; 2018. p. 13-22.

18. Hirata H, Kergoat D. Divisão sexual do trabalho profissional e doméstico: Brasil, França e Japão. In: Costa AO, Sorj B, Bruschini C, et al., organizadoras. Mercado de trabalho e gênero: comparações internacionais. Rio de Janeiro: FGV; 2008. p. 264-278.

19. Hirata H. Globalização e divisão sexual do trabalho. Cad. Pagu. 2002 [acesso em 2021 maio 19]; (17/18):139-
156. Disponível em: https://doi.org/10.1590/S010483332002000100006.

20. Hirata H. Por quem os sinos dobram? Globalização e divisão sexual do trabalho. In: Emílio M, Teixeira M, Nobre M, et al., organizadoras. Trabalho e cidadania ativa para as mulheres: desafios para as políticas públicas. São Paulo: Coordenadoria Especial da Mulher; 2003. p. 15-30.

21. Hirata H, Zarifian P. Força e Fragilidade do modelo japonês. Estud. av. 1991 [acesso em 2021 maio 19]; 5(12):173-185. Disponível em: http://dx.doi. org/10.1590/S0103-40141991000200011.

22. Hirata H. Globalização e divisão sexual do trabalho numa perspectiva comparada. In: Guimarães NA, Hirata H, Sugita K, organizadoras. Trabalho flexível, empregos precários? Uma comparação Brasil, França, Japão. São Paulo: Edusp; 2009. p. 145-167.

23. Hirata H. O cuidado em domicílio na França e no Brasil. In: Abreu ARP, Hirata H, Lombardi MR, organizadoras. Gênero e trabalho no Brasil e na França: perspectivas interseccionais. São Paulo: Boitempo; 2016. p. 193-202.

24. Hirata H. O trabalho de cuidado: comparando Brasil, França e Japão. Sur - Rev. int. dir. hum. 2016 [acesso em 2021 maio 19]; 13(24):53-64. Disponível em: https:// sur.conectas.org/wp-content/uploads/2017/02/5-sur-24-por-helena-hirata.pdf.

25. Hirata H. Comparando relações de cuidado: Brasil, França e Japão. Estud. av. 2020 [acesso em 2021 maio 19]; 98(34):25-40. Disponível em: https://doi. org/10.1590/s0103-4014.2020.3498.003.

26. Hirata H, Kergoat D. Rapports sociaux de sexe et psychopathologie du travail. In: Dejours C, organizador. Plaisir et souffrance dans le travail, Partie 2. Paris: Martin Média; 1988. p. 163-203.

27. Molinier P. Psicodinâmica do trabalho e relações sociais de sexo: um itinerário interdisciplinar. 19882002. Prod. 2004 [acesso em 2021 maio 19]; 14(3):14- 
26. Disponível em: https://doi.org/10.1590/S010365132004000300003 .

28. Brito JC, Bercot R, Horellou-Lafarge C, et al. Saúde, gênero e reconhecimento no trabalho das professoras: convergências e diferenças no Brasil e na França. Physis. 2014 [acesso em 2021 maio 19]; 24(2):589-605. Disponível em: https://doi.org/10.1590/S010373312014000200014
29. Canguilhem G. O normal e o patológico. Rio de Janeiro: Forense Universitária; 1995.

30. Brito J. Saúde, trabalho e modos sexuados de viver. Rio de Janeiro: Fiocruz; 1999.

Recebido em 31/08/2020

Aprovado em 05/05/2021

Conflito de interesses: inexistente

Suporte financeiro: não houve 